\title{
Quality Improvement Guidelines for Radiofrequency Ablation of Liver Tumours
}

\author{
Laura Crocetti · Thierry de Baere • \\ Riccardo Lencioni
}

Received: 5 October 2009/Accepted: 5 October 2009/Published online: 19 November 2009

(C) Springer Science+Business Media, LLC and the Cardiovascular and Interventional Radiological Society of Europe (CIRSE) 2009

\begin{abstract}
The development of image-guided percutaneous techniques for local tumour ablation has been one of the major advances in the treatment of liver malignancies. Among these methods, radiofrequency ablation (RFA) is currently established as the primary ablative modality at most institutions. RFA is accepted as the best therapeutic choice for patients with early-stage hepatocellular carcinoma (HCC) when liver transplantation or surgical resection are not suitable options [1, 2]. In addition, RFA is considered a viable alternate to surgery (1) for inoperable patients with limited hepatic metastatic disease, especially from colorectal cancer, and (2) for patients deemed ineligible for surgical resection because of extent and location of the disease or concurrent medical conditions [3]. These guidelines were written to be used in quality-improvement programs to assess RFA of HCC and liver metastases. The most important processes of care are (1) patient selection, (2) performing the procedure, and (3) monitoring the patient. The outcome measures or indicators for these processes are indications, success rates, and complication rates.
\end{abstract}

L. Crocetti $(\bowtie) \cdot$ R. Lencioni

Division of Diagnostic Imaging and Intervention,

Department of Hepatology, Liver Transplants, and Infectious

Diseases, University of Pisa, Pisa, Italy

e-mail: 1.crocetti@med.unipi.it

T. de Baere

Department of Interventional Radiology, Institut de

Cancérologie Gustave Roussy, Villejuif, France

\section{Definitions}

Ablative Margin

This is the region ablated beyond the borders of the tumour to achieve complete tumour destruction. Ideally, it should measure $0.5-1.0 \mathrm{~cm}$ wide.

Complete Ablation

This is the nonenhancing area, including the tumour and the ablative margin, on contrast-enhanced imaging modalities.

\section{Complications}

Complications can be stratified on the basis of outcome by using the society of interventional radiology (SIR) standard table. Major complications result in admission to a hospital for therapy (for outpatient procedures), an unplanned increase in the level of care, prolonged hospitalization, permanent adverse sequelae, or death. Minor complications result in no sequelae, and they may require nominal therapy or a short hospital stay for observation (generally overnight). Major and minor complications and side effects should be reported on the basis of the number of ablation sessions on a per-session basis.

\section{Electrode (Radiofrequency Applicator)}

One or multiple electrodes are inserted directly into the tumour to deliver RF energy current. Electrodes can be monopolar or bipolar, and they can have different designs (multitined expandable, internally cooled, perfused). 
- Monopolar Electrode This has a single active electrode applicator, with current dissipated at one or several return grounding pads.

- Bipolar Electrode This consists in two electrode applicators or in a single array containing both the active and return electrodes.

- Multitined Expandable Electrode This has multiple electrode tines that expand from a larger needle cannula.

- Internally Cooled Electrode This electrode has an internal lumen that is perfused by saline without coming into direct contact with patient body tissue.

- Perfused Electrode The tip of the electrode has small apertures that allow the fluid (usually saline) to come in contact with the tissue.

\section{Heat-Sink Effect}

This is convective cooling by adjacent blood vessels, usually $\geq 3 \mathrm{~mm}$, when ablated tissues are heated. It can negatively affect the results of RFA because it can potentially remove heat before complete tumour ablation is achieved.

\section{Hydro/Gas Dissection}

This is the instillation of liquid (dextrose 5\%, sterile water) or gas (air, carbon dioxide) between the area of ablation and the structure vulnerable to heating damage (usually the bowel).

\section{Incomplete Ablation}

This is the presence of residual unablated tumour, which is seen as peripheral irregular enhancement at imaging. It often grows in a scattered, nodular, or eccentric pattern.

\section{Local Tumour Progression}

This is the appearance at follow-up of foci of untreated disease in tumours that were previously considered to be completely ablated.

\section{Overall Survival}

This is the time from inclusion in the study to death. Patients who are alive at the end of follow-up are censored.

\section{Radiofrequency Ablation}

This is coagulation induction from all electromagnetic energy sources with frequencies $<30 \mathrm{MHz}$. For tumour ablation purposes, the frequency is usually in the range of 375 to $500 \mathrm{kHz}$.

\section{Technical Success}

This is considered when treatment of the tumour was performed according to protocol and complete tumour coverage is assessed either during or immediately after the procedure.

Transient Hyperechoic Zone

This is the transient ( $>30-90 \mathrm{~min}$ ) zone of increased echogenicity seen at US within and surrounding a tumour during and immediatelyafter RFA.

\section{Indications}

$\mathrm{HCC}$

RFA is the therapy of choice in very early and early HCC according to the Barcelona Clinic Liver Cancer (BCLC) classification (Table 1) when patients are not candidates for either liver resection or transplantation. Patients are required to have a single tumour smaller or as many as three nodules $<3 \mathrm{~cm}$ each, no evidence of vascular invasion or extrahepatic spread, performance status test of 0 , and liver cirrhosis in Child-Pugh class A or $\mathrm{B}$.

\section{Liver Metastases}

\section{Primary Tumour Histotype}

RFA is generally indicated for nonsurgical patients with colorectal cancer oligometastases isolated to the liver. Selected patients with limited hepatic and pulmonary colorectal metastatic disease, however, may qualify for percutaneous treatment if extrahepatic disease is deemed curable. In patients with hepatic metastases from other primary cancers, promising initial results have been reported in the treatment of breast and endocrine tumours.

\section{Number of Lesions}

The number of lesions should not be considered an absolute contraindication to RFA if successful treatment of all metastatic deposits can be accomplished. Nevertheless, most centres preferentially treat patients with $\leq 5$ lesions.

\section{Tumour Size}

The target tumour should not exceed $3 \mathrm{~cm}$ at its longest axis to achieve best rates of complete ablation using most of the currently available devices. 
Table 1 BCLC classification in patients diagnosed with $\mathrm{HCC}$

$P S$ performance status

\begin{tabular}{ll}
\hline Very early stage & PS 0, Child-Pugh A, single HCC $<2 \mathrm{~cm}$ \\
Early stage & PS 0, Child-Pugh A to B, single HCC or $3 \mathrm{HCCs}<3 \mathrm{~cm}$ \\
Intermediate stage & PS 0, Child-Pugh A to B, multinodular HCC \\
Advanced stage & PS 1 to 2, Child-Pugh A to B, portal neoplastic invasion, \\
& nodal metastases, distant metastases \\
Terminal stage & PS $>2$, Child-Pugh C
\end{tabular}

\section{Tumour Location}

Pretreatment imaging must carefully define the location of each lesion with respect to surrounding structures as follows:

- Lesions located on the surface of the liver can be considered for RFA, although their treatment requires adequate expertise and may be associated with a higher risk of complications.

- Thermal ablation of superficial lesions that are adjacent to any part of the gastrointestinal tract must be avoided because of the risk of thermal injury of the gastric or bowel wall. The colon appears to be at greater risk than the stomach or small bowel for thermally mediated perforation. Gastric complications are rare, most likely owing to the relatively greater wall thickness of the stomach or the rarity of surgical adhesions along the gastrohepatic ligament. Mobility of the small bowel may also provide the bowel with greater protection compared with the relatively fixed colon. The use of special techniques, such as intraperitoneal injection of dextrose to displace the bowel, can be considered in such instances.

- Treatment of lesions adjacent to the hepatic hilum increases the risk of thermal injury of the biliary tract. This tumour location represents a relative contraindication to RFA. In experienced hands, thermal ablation of tumours located near the gallbladder has been shown to be feasible, although associated in most cases with self-limited iatrogenic cholecystitis.

- Thermal ablation of lesions adjacent to hepatic vessels is possible because flowing blood usually protects the vascular wall from thermal injury. In this case, however, the risk of incomplete treatment of the neoplastic tissue close to the vessel may increase due to heat loss by convection.

\section{Physician Credentialing}

Before treatment, all patients with liver tumours who are considered for RFA should undergo a thorough clinical evaluation by a multidisciplinary team, including an interventional radiologist, a hepatologist, an oncologist, a surgeon, and an anesthesiologist. The core of physiological knowledge required for the interventional radiologist includes understanding liver anatomy, liver tumour diagnosis, and radiologic and non radiologic treatment options.

\section{Imaging Guidance and Monitoring}

Targeting of the lesion can be performed with ultrasound, computed tomography (CT), or magnetic resonance imaging (MRI). The guidance system is chosen largely on the basis of tumour visibility, operator preference, and local availability of dedicated equipment, such as CT fluoroscopy or open MRI systems. The transient hyperechoic zone that is seen on ultrasound within and surrounding a tumour during and immediately after RFA can be used as an approximate guide to the extent of tumour destruction. It is not sufficient to evaluate immediate treatment effectiveness, and follow-up imaging is mandatory. MRI currently is the only imaging modality with validated techniques for real-time temperature monitoring.

\section{Anesthesiology Care}

Thermal ablation is usually performed with the patient under intravenous sedation or general anaesthesia with standard cardiac, pressure, and oxygen monitoring. American Society of Anesthesiologists (ASA) score (Appendix) can be used to assess patient physical status before RFA. Patients with $\leq$ ASA III score can be treated.

\section{Posttreatment Assessment and Follow-Up}

Contrast-enhanced CT or MRI are recognized as the standard modalities with which to assess treatment outcome. CT and MRI results obtained 4-6 weeks after treatment show successful ablation as a nonenhancing area with or without a peripheral enhancing rim. The enhancing rim that may be observed along the periphery of the ablation zone appears to be a relatively concentric, symmetric, and uniform process in an area with smooth inner margins. This transient finding represents a benign physiologic response to thermal injury (reactive hyperemia initially and fibrosis and giant cell reaction subsequently). Benign periablational enhancement must be differentiated from irregular peripheral 
enhancement due to residual tumour that occurs at the treatment margin. Compared with benign periablational enhancement, residual unablated tumour often grows in scattered, nodular, or eccentric patterns. Contrast-enhanced ultrasound can be performed after the end of the procedure and may allow initial evaluation of treatment effects.

Later follow-up imaging studies should be aimed at detecting local tumour progression, development of new hepatic lesions, or emergence of extrahepatic disease. A recommended follow-up protocol includes CT or MRI studies at 3, 6, 9, and 12 months after treatment and at 6-month intervals thereafter for the next 3 years.

\section{Contraindications}

Contraindications for RFA are as follows:

1. tumour located $<1 \mathrm{~cm}$ from the main biliary duct (due to risk of delayed stenosis of the main biliary tract);

2. intrahepatic bile duct dilation;

3. anterior exophytic location of the tumour (due to the risk of tumour seeding);

4. bilioenteric anastomosis; and

5. untreatable/unmanageable coagulopathy.

\section{Clinical Results: HCC}

\section{Technique Effectiveness}

RFA yields satisfactory local tumour control in treating small HCCs, with a complete ablation rate on imaging of approximately $90 \%$ in tumours $>3 \mathrm{~cm}$ [4-8]. Histological data from explanted liver specimens in patients who have undergone RFA showed that tumour size and presence of large $(\leq 3 \mathrm{~mm})$ abutting vessels significantly affect local treatment effect. Complete tumour necrosis was pathologically shown in $83 \%$ of tumours $<3 \mathrm{~cm}$ and $88 \%$ of tumours located in a nonperivascular space [9]. Comparison with percutaneous ethanol injection (PEI) in five randomized trials [4-8] showed that RFA has a higher local anticancer effect than PEI, thus leading to better local control of the disease (Table 2). Consequently there is no room per PEI in HCC amenable to RFA.

\section{Survival}

Five randomized trials compared RFA with PEI for local ablation of early-stage HCC (Table 2). The two European trials failed to show a statistically significant difference in overall survival between patients who received RFA compared with those receiving PEI [4, 8]. However, survival advantages were identified in three Asian studies [5-7]. These data were recently pooled in two independent meta-analysis, and the survival benefit of patients with small HCCs who received RFA was confirmed [10, 11]. Therefore, RFA is the preferred percutaneous treatment for patients with early-stage HCC on the basis of more consistent local tumour control and better survival outcomes.

Recently, the long-term survival outcomes of RFAtreated patients were reported (Table 3) [12-17]. In patients who underwent RFA, survival depended on the severity of underlying cirrhosis and tumour stage. Patients in Child-Pugh class A with early stage HCC had a 5-year
Table 2 Randomized studies comparing RFA and PEI in the treatment of early-stage $\mathrm{HCC}$

a Includes initial treatment failure (incomplete response) and late treatment failure (local recurrence/progression)

\begin{tabular}{|c|c|c|c|c|c|c|}
\hline Author & $\begin{array}{l}\text { No. of } \\
\text { patients }\end{array}$ & Tumour size & $\begin{array}{l}\text { Complete } \\
\text { ablation }(\%)\end{array}$ & $\begin{array}{l}\text { Treatment } \\
\text { failure }(\%)^{\mathrm{a}}\end{array}$ & $\begin{array}{l}\text { Three-year } \\
\text { overall survival }\end{array}$ & $P$ \\
\hline \multicolumn{7}{|c|}{ Lencioni et al. [4] } \\
\hline $\mathrm{RF}$ & 52 & 1 & 91 & 8 & 81 & \multirow[t]{2}{*}{$>0.05$} \\
\hline PEI & 50 & $\begin{array}{l}\mathrm{HCC}<5 \mathrm{~cm} \text { or } \\
3 \mathrm{HCCs}<3 \mathrm{~cm}\end{array}$ & 82 & 34 & 73 & \\
\hline \multicolumn{7}{|c|}{ Lin et al. [5] } \\
\hline $\mathrm{RF}$ & 52 & 1-3 HCCs & 96 & 17 & 74 & \multirow[t]{2}{*}{0.014} \\
\hline PEI & 52 & $<4 \mathrm{~cm}$ & 88 & 45 & 50 & \\
\hline \multicolumn{7}{|c|}{ Shiina et al. [6] } \\
\hline $\mathrm{RF}$ & 118 & 1-3 HCCs & 100 & 2 & 80 & \multirow[t]{2}{*}{0.02} \\
\hline PEI & 114 & $<3 \mathrm{~cm}$ & 100 & 11 & 63 & \\
\hline \multicolumn{7}{|c|}{ Lin et al. [7] } \\
\hline $\mathrm{RF}$ & 62 & 1-3 HCCs & 97 & 16 & 74 & \multirow[t]{2}{*}{0.031} \\
\hline PEI & 62 & $<3 \mathrm{~cm}$ & 89 & 42 & 51 & \\
\hline \multicolumn{7}{|c|}{ Brunello et al. [8] } \\
\hline $\mathrm{RF}$ & 70 & 1-3 HCCs & 96 & 34 & 59 & \multirow[t]{2}{*}{$>0.05$} \\
\hline PEI & 69 & $<3 \mathrm{~cm}$ & 66 & 64 & 57 & \\
\hline
\end{tabular}


Table 3 Studies reporting long-term survival outcomes of patients with early-stage HCC who underwent percutaneous RFA

$N A$ not available

${ }^{\text {a }}$ Patients who received radiofrequency ablation as primary treatment

${ }^{b}$ Patients who received radiofrequency ablation for recurrent tumour after previous treatment including resection, ethanol injection, microwave ablation, and transarterial embolization

\begin{tabular}{|c|c|c|c|c|}
\hline \multirow[t]{2}{*}{ Author } & \multirow[t]{2}{*}{ No. of patients } & \multicolumn{3}{|c|}{ Survival $(\%)$} \\
\hline & & 1 year & 3 years & 5 years \\
\hline \multicolumn{5}{|l|}{ Lencioni et al. [12] } \\
\hline Child-Pugh A, $1 \mathrm{HCC}<5 \mathrm{~cm}$ or $3 \mathrm{HCCs}<3 \mathrm{~cm}$ & 144 & 100 & 76 & 51 \\
\hline $1 \mathrm{HCC}<5 \mathrm{~cm}$ & 116 & 100 & 89 & 61 \\
\hline Child-Pugh $\mathrm{B}, 1 \mathrm{HCC}<5 \mathrm{~cm}$ or $3 \mathrm{HCCs}<3 \mathrm{~cm}$ & 43 & 89 & 46 & 31 \\
\hline \multicolumn{5}{|l|}{ Tateishi et al. [13] } \\
\hline Naive patients ${ }^{\mathrm{a}}$ & 319 & 95 & 78 & 54 \\
\hline Nonnaive patients ${ }^{\mathrm{b}}$ & 345 & 92 & 62 & 38 \\
\hline Cabassa et al. [14] & 59 & 94 & 65 & 43 \\
\hline \multicolumn{5}{|l|}{ Choi et al. [15] } \\
\hline Child-Pugh A, $1 \mathrm{HCC}<5 \mathrm{~cm}$ or $3 \mathrm{HCCs}<3 \mathrm{~cm}$ & 359 & NA & 78 & 64 \\
\hline Child-Pugh $\mathrm{B}, 1 \mathrm{HCC}<5 \mathrm{~cm}$ or $3 \mathrm{HCCs}<3 \mathrm{~cm}$ & 160 & NA & 49 & 38 \\
\hline \multicolumn{5}{|l|}{ Takahashi et al. [16] } \\
\hline Child-Pugh A, $1 \mathrm{HCC}<5 \mathrm{~cm}$ or $3 \mathrm{HCCs}<3 \mathrm{~cm}$ & 171 & 99 & 91 & 77 \\
\hline \multicolumn{5}{|l|}{ Hiraoka et al. [17] } \\
\hline Child-Pugh A to B & 105 & NA & 88 & 59 \\
\hline
\end{tabular}

survival rate of 61 to $77 \%$, whereas patients with a single tumour $\leq 2 \mathrm{~cm}$ had a 5 -year survival rate of $68 \%$.

\section{Clinical Results: Colorectal Cancer Liver Metastases}

\section{Technique Effectiveness}

Many studies have investigated the use of RFA in the treatment of limited colorectal cancer hepatic metastatic disease in patients who were excluded from surgery. Two early studies reported rates of complete response that did not exceed $60-70 \%[18,19]$. Subsequently, owing to the advances in RFA technique and probably to the treatment of smaller tumours, reported rates of successful local tumour control after RFA treatment increased substantially. In two series, RFA allowed eradication of $91 \%$ of 100 metastases and $97 \%$ of 74 metastases, respectively [20, 21].

\section{Survival}

Recently, data on long-term survival of nonsurgical patients with hepatic colorectal metastases who underwent RFA have been reported (Table 4) [22-28]. In particular, in three series including patients with $\leq 5$, each $\leq 5 \mathrm{~cm}$, the 5-year survival rate ranged $24-44 \%$ at 5 years $[22,23,26]$. When RFA was performed in patients with small $(<4 \mathrm{~cm})$ solitary hepatic colorectal metastases, a 40\% 5-year survival rate was demonstrated [29]. These figures are substantially higher than those obtained with any chemotherapy regimens and provide indirect evidence that RFA therapy improves survival in patients with limited hepatic metastatic disease. This conclusion is supported by the interim
Table 4 Studies reporting long-term survival outcomes of patients with colorectal hepatic metastases who underwent percutaneous RFA

\begin{tabular}{lrlll}
\hline Author & \multirow{2}{*}{$\begin{array}{l}\text { No. of } \\
\text { patients }\end{array}$} & \multicolumn{3}{l}{ Survival (\%) } \\
\cline { 3 - 5 } & & 1 year & 3 years & 5 years \\
\hline Solbiati et al. [22] & 117 & 93 & 46 & - \\
Lencioni et al. [23] & 423 & 86 & 47 & 24 \\
Gillams et al. [24] & 73 & 91 & 28 & 25 \\
Machi et al. [25] & 100 & 90 & 42 & 30 \\
Jackobs et al. [26] & 68 & 96 & 68 & - \\
Sorensen et al. [27] & 102 & 87 & 46 & $26^{\mathrm{a}}$ \\
Veltri et al. [28] & 122 & 79 & 38 & 22 \\
\hline
\end{tabular}

a 4-year survival

analysis of a randomized controlled trial comparing chemotherapy plus RFA versus chemotherapy alone in colorectal cancer metastatic to the liver [30].

\section{Complications}

Early major complications associated with RFA occur in 2.2-3.1\% of patients and include intraperitoneal bleeding, liver abscess, intestinal perforation, pneumothorax and haemothorax, bile duct stenosis, and tumour seeding $(0.5 \%)$; the procedure mortality rate is $0.1-0.5 \%$ (Table 5 ). The minor complication rate ranges from $5 \%$ to $8.9 \%$. The most common causes of death are sepsis, hepatic failure, colon perforation, and portal vein thrombosis, whereas the most common complications are intraperitoneal bleeding, hepatic abscess, bile duct injury, hepatic decompensation, and grounding pad burns. Minor complications and side 
Table 5 Reported and acceptable rate of major complications

\begin{tabular}{lll}
\hline $\begin{array}{l}\text { Specific major complications } \\
\text { per session }\end{array}$ & $\begin{array}{l}\text { Reported } \\
\text { rate }(\%)\end{array}$ & $\begin{array}{l}\text { Suggested } \\
\text { threshold }(\%)\end{array}$ \\
\hline Hemorrhage requiring transfusion & 1 & 2 \\
Bowel perforation & 0.3 & 0.6 \\
Abscess & 0.3 & 0.6 \\
Hemothorax & 0.1 & 0.2 \\
Tumour seeding & 0.5 & 1 \\
Hepatic decompensation & 0.3 & 0.6 \\
Bile duct injury & 0.1 & 0.2 \\
Grounding pad burns & 0.1 & 0.2 \\
Death & 0.5 & 1 \\
\hline
\end{tabular}

effects are usually transient and self-limiting [31-33]. An uncommon late complication of RFA can be tumour seeding along the needle track. In patients with HCC, tumour seeding occurred in $8(0.5 \%)$ of 1,610 cases in a multicentre survey [31] and in $1(0.5 \%)$ of 187 cases in a single-institution series [12]. Lesions with subcapsular location and an invasive tumoural pattern, as shown by a poor differentiation degree, seem to be at higher risk for such a complication [34].

\section{Appendix A: American Society of Anesthesiologists (ASA) Physical Status Classification System}

I Normal healthy patient

II Patient with mild systemic disease

III Patient with severe systemic disease

IV Patient with severe systemic disease that is a constant threat to life

$\mathrm{V}$ Moribund patient who is not expected to survive without surgery

VI Patient declared brain-dead whose organs are removed for donor purposes

\section{References}

1. Bruix J, Sherman M, Llovet JM et al (2001) EASL panel of experts on HCC. Clinical management of hepatocellular carcinoma. Conclusions of the Barcelona-2000 EASL Conference. European Association for the Study of the Liver. J Hepatol 35:421-430

2. Bruix J, Sherman M (2005) Management of hepatocellular carcinoma. Hepatology 42:1208-1236

3. Stang A, Fischbach R, Teichmann W, Bokemeyer C, Braumann D (2009) A systematic review on the clinical benefit and role of radiofrequency ablation as treatment of colorectal liver metastases. Eur J Cancer 45:1748-1756

4. Lencioni R, Allgaier HP, Cioni D et al (2003) Small hepatocellular carcinoma in cirrhosis: randomized comparison of radiofrequency thermal ablation versus percutaneous ethanol injection. Radiology 228:235-240
5. Lin SM, Lin CJ, Lin CC et al (2004) Radiofrequency ablation improves prognosis compared with ethanol injection for hepatocellular carcinoma $\leq 4 \mathrm{~cm}$. Gastroenterology 127:1714-1723

6. Shiina S, Teratani T, Obi S et al (2005) A randomized controlled trial of radiofrequency ablation versus ethanol injection for small hepatocellular carcinoma. Gastroenterology 129:122-130

7. Lin SM, Lin CJ, Lin CC, Hsu CW, Chen YC (2005) Randomised controlled trial comparing percutaneous radiofrequency thermal ablation, percutaneous ethanol injection, and percutaneous acetic acid injection to treat hepatocellular carcinoma of $3 \mathrm{~cm}$ or less. Gut 54:1151-1156

8. Brunello F, Veltri A, Carucci P et al (2008) Radiofrequency ablation versus ethanol injection for early hepatocellular carcinoma: A randomized controlled trial. Scand J Gastroenterol 43:727-735

9. Lu DS, Yu NC, Raman SS et al (2005) Radiofrequency ablation of hepatocellular carcinoma: treatment success as defined by histologic examination of the explanted liver. Radiology 234:954-960

10. Orlando A, Leandro G, Olivo M, Andriulli A, Cottone M (2009) Radiofrequency thermal ablation vs. percutaneous ethanol injection for small hepatocellular carcinoma in cirrhosis: metaanalysis of randomized controlled trials. Am J Gastroenterol 104:514-524

11. Cho YK, Kim JK, Kim MY, Rhim H, Han JK (2009) Systematic review of randomized trials for hepatocellular carcinoma treated with percutaneous ablation therapies. Hepatology 49:453-459

12. Lencioni R, Cioni D, Crocetti L et al (2005) Early-stage hepatocellular carcinoma in cirrhosis: long-term results of percutaneous image-guided radiofrequency ablation. Radiology 234: 961-967

13. Tateishi R, Shiina S, Teratani $\mathrm{T}$ et al (2005) Percutaneous radiofrequency ablation for hepatocellular carcinoma. Cancer 103:1201-1209

14. Cabassa P, Donato F, Simeone F et al (2006) Radiofrequency ablation of hepatocellular carcinoma: long-term experience with expandable needle electrodes. Am J Roentgenol 185(Suppl):S316-S321

15. Choi D, Lim HK, Rhim H et al (2007) Percutaneous radiofrequency ablation for early-stage hepatocellular carcinoma as a first- line treatment: long-term results and prognostic factors in a large single-institution series. Eur Radiol 17:684-692

16. Takahashi S, Kudo M, Chung $H$ et al (2007) Initial treatment response is essential to improve survival in patients with hepatocellular carcinoma who underwent curative radiofrequency ablation therapy. Oncology 72(Suppl):S98-S103

17. Hiraoka A, Horiike N, Yamashita Y et al (2008) Efficacy of radiofrequency ablation therapy compared to surgical resection in 164 patients in Japan with single hepatocellular carcinoma smaller than $3 \mathrm{~cm}$, along with report of complications. Hepatogastroenterology 55:2171-2174

18. Lencioni R, Goletti O, Armillotta N et al (1998) Radio-frequency thermal ablation of liver metastases with a cooled-tip electrode needle: results of a pilot clinical trial. Eur Radiol 8:1205-1211

19. Solbiati L, Goldberg SN, Ierace T et al (1997) Hepatic metastases: percutaneous radio-frequency ablation with cooled-tip electrodes. Radiology 205:367-373

20. De Baere T, Elias D, Dromain C et al (2000) Radiofrequency ablation of 100 hepatic metastases with a mean follow-up of more than 1 year. Am J Roentgenol 175:1619-1625

21. Helmberger T, Holzknecht N, Schopf U et al (2001) Radiofrequency ablation of liver metastases. Technique and initial results. Radiologe 41:69-76

22. Solbiati L, Livraghi T, Goldberg SN et al (2001) Percutaneous radio-frequency ablation of hepatic metastases from colorectal cancer: long-term results in 117 patients. Radiology 221:159-166 
23. Lencioni R, Crocetti L, Cioni D et al (2004) Percutaneous radiofrequency ablation of hepatic colorectal metastases. Technique, indications, results, and new promises. Invest Radiol 39:689-697

24. Gillams AR, Lees WR (2004) Radio-frequency ablation of colorectal liver metastases in 167 patients. Eur Radiol 14:22612267

25. Machi J, Oishi AJ, Sumida K et al (2006) Long-term outcome of radiofrequency ablation for unresectable liver metastases from colorectal cancer: evaluation of prognostic factors and effectiveness in first- and second-line management. Cancer J 12:318326

26. Jackobs TF, Hoffmann RT, Trumm C et al (2006) Radiofrequency ablation of colorectal liver metastases: mid-term results in 68 patients. Anticancer Res 26:671-680

27. Sorensen SM, Mortensen FV, Nielsen DT (2007) Radiofrequency ablation of colorectal liver metastases: long-term survival. Acta Radiol 48:253-258

28. Veltri A, Sacchetto P, Tosetti I, Pagano E, Fava C, Gandini G (2008) Radiofrequency ablation of colorectal liver metastases: small size favorably predicts technique effectiveness and survival. Cardiovasc Intervent Radiol 31:948-956
29. Gillams AR, Lees WR (2008) Five-year survival following radiofrequency ablation of small, solitary, hepatic colorectal metastases. J Vasc Interv Radiol 19:712-717

30. Ruers T, van Coevorden F, Pierie J et al (2008) Radiofrequency ablation combined with chemotherapy for unresectable colorectal liver metastases: interim results of a randomised phase II study of the EORTC-NCRI CCSG-ALM Intergroup 40004 (CLOCC). J Clin Oncol 26(Suppl 20):4012

31. Livraghi T, Solbiati L, Meloni MF et al (2003) Treatment of focal liver tumors with percutaneous radio-frequency ablation: complications encountered in a multicentre study. Radiology 26:441451

32. De Baere T, Risse O, Kuoch V et al (2003) Adverse events during radiofrequency treatment of 582 hepatic tumors. Am J Roentgenol 181:695-700

33. Bleicher RJ, Allegra DP, Nora DT et al (2003) Radiofrequency ablation in 447 complex unresectable liver tumors: lessons learned. Ann Surg Oncol 10:52-58

34. Llovet JM, Vilana R, Bru C et al (2001) Barcelona Clinic Liver Cancer (BCLC) Group. Increased risk of tumor seeding after percutaneous radiofrequency ablation for single hepatocellular carcinoma. Hepatology 33:1124-1129 